\title{
Role of echocardiography in diagnosis and treatment in patients with infective endocarditis
}

\section{Elizabeta Srbinovska Kostovska* \\ University Clinic of \\ Cardiology, Medical Faculty, \\ Skopje, Macedonia}

\author{
KEYWORDS: infective endocarditis, echocardiography, vegetation, perivalvular abscess \\ CITATION: Cardiol Croat. 2015;10(3-4):92. | DOI: http://dx.doi.org/10.15836/ccar.2015.92 \\ ORCID: Elizabeta Srbinovska Kostovska, http://orcid.org/0000-0002-4881-6821
}

*ADDRESS FOR CORRESPONDENCE: Elizabeta Srbinovska Kostovska, University Clinic of Cardiology, Zenevska br. 19, 1000 Skopje, Republic of Macedonia. Phone: +389-70-387-153. E-mail: esrbinovska@yahoo.com

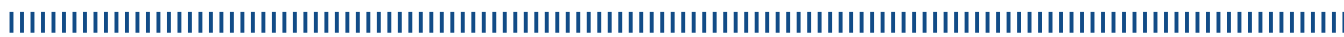
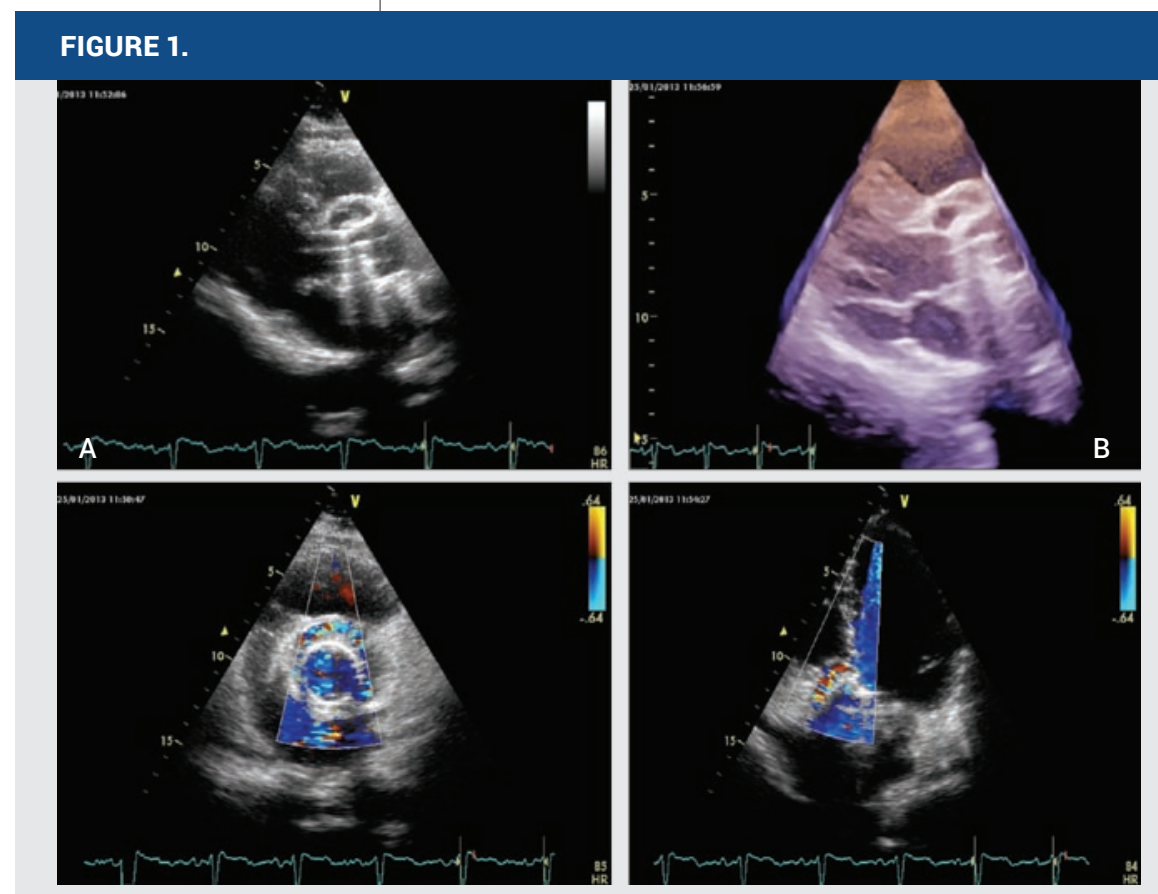

A. Two-dimensional image on parasternal long axis in patients with Ao prosthesis. There is a paravalvular abscess under the prosthesis, which is better seen in three-dimensional echocardiography (B). C. Two-dimensional echocardiography in short axis of the Ao plane. There is a color flow in the abscess, and on D. Two-dimensional three chamber view we can see communication of the perivalvular abscess with left ventricle.
Echocardiography plays a key role in each of the steps of assessment of infective endocarditis (IE): the diagnosis, risk stratification, time for operation and follow up. The major echocardiographic criteria for IE are discovering vegetations, abscess, new valvular regurgitation and prosthesis dehiscence.

According to the recent ESC recommendation for diagnosis and assessment of patients with IE, in all patients with clinical suspicion of IE, transthoracic echocardiography (TTE) is the first step of assessment. In all patients with prosthetic endocarditis, poor quality of TTE image and in majority of patients with positive TTE for IE, transesophageal echocardiography (TEE) is recommended. If the TTE examination is negative, with low

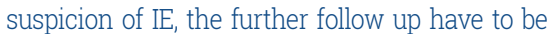
stop. And, if TTE is negative, but there is a high suspicion of IE, TTE and TEE have to be repeated in 7-10 days. ${ }^{1-3}$

Anatomical features of IE which can be discovered with echocardiography examination have specific characteristics: 1. Presence of vegetation, which can be oscillating or non-oscillating intracardiac mass typically attached on the low pressure side of the valve, but may be located anywhere in the valvular and subvalvular apparatus and endocardium; $\mathbf{2}$. Destructive valve lesion like perforation or prolapse of the valve; $\mathbf{3}$. Abscess formation (more frequent located in Ao valve and in prosthetic valve endocarditis), which can be complicated with perivalvular pseudo-aneurysm and fistulization. Color Doppler echocardiography and continuous wave Doppler are useful modalities for assessment severity of valvular lesion. Three dimensional echocardiography allows better assessment of cardiac morphology and structure, and is particularly useful in assessment complication (Figure 1). Other cardiac imaging modalities (multislice computed tomography (CT, magnetic resonance, 18Ffluorodesoxyglucose PET-CT, and single photon emission computed tomography (SPECT) /CT sometimes can be used in discovering complications in IE.

CONCLUSION: Echocardiography is powerful tool for the diagnosis of endocarditis, the assessment of the severity of the disease, the prediction of short-term and long-term prognosis, the prediction of embolic risk, discovering complications of the disease, for decision to operate or not and for the choice of optimal time for operation and the follow-up patients with Infective endocarditis.

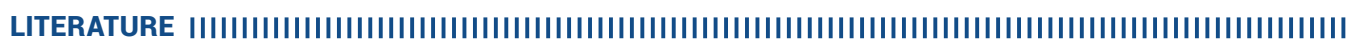
Habib G, Hoen B, Tornos P, Thuny F, Prendergast B, Vilacosta I, et al; ESC Committee for Practice Guidelines. Guidelines on the prevention, diagnosis, and treatment of infective endocarditis (new version 2009): the Task Force on the Prevention, Diagnosis, and Treatment of Infective Endocarditis of the European Society of Cardiology (ESC). Endorsed by the European Society of Clinical Microbiology and Infectious Diseases (ESCMID) and the International Society of Chemotherapy (ISC) for Infection and Cancer. Eur Heart J. 2009;30(19):2369-413. DOI: http://dx.doi.org/10.1093/eurheartj/ehp285

2. Habib G, Badano L, Tribouilloy C, Vilacosta I, Zamorano JL, Galderisi M, et al; European Association of Echocardiography. Recommendation for the practice of echocardiography in infective endocarditis. Eur Heart J. 2010;11:201-19. DOI: http://dx.doi.org/10.1093/ejechocard/jeg004

3. Bruun NE, Habib G, Thuny F, Sogaard P. Cardiac imaging in infectious endocarditis. Eur Heart J. 2014;35:624-32.

DOI: http://dx.doi.org/10.1093/eurheartj/eht274 